Cite this: J. Mater. Chem. B, 2013, 1, 6157

Received 25th July 2013

Accepted 26th September 2013

DOI: $10.1039 / \mathrm{c} 3 \mathrm{tb} 21031 \mathrm{f}$

www.rsc.org/MaterialsB

\section{Bioactive films produced from self-assembling peptide amphiphiles as versatile substrates for tuning cell adhesion and tissue architecture in serum-free conditions $\uparrow$}

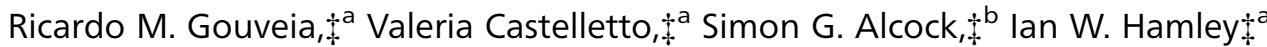 \\ and Che J. Connont*a
}

The development of versatile bioactive surfaces able to emulate in vivo conditions is of enormous importance to the future of cell and tissue therapy. Tuning cell behaviour on two-dimensional surfaces so that the cells perform as if they were in a natural three-dimensional tissue represents a significant challenge, but one that must be met if the early promise of cell and tissue therapy is to be fully realised. Due to the inherent complexities involved in the manufacture of biomimetic three-dimensional substrates, the scaling up of engineered tissue-based therapies may be simpler if based upon proven two-dimensional culture systems. In this work, we developed new coating materials composed of the self-assembling peptide amphiphiles (PAs) $C_{16} G_{3} R G D$ (RGD) and $C_{16} G_{3} R G D S$ (RGDS) shown to control cell adhesion and tissue architecture while avoiding the use of serum. When mixed with the $\mathrm{C}_{16}$ ETTES diluent PA at 13:87 (mol mol $\left.{ }^{-1}\right)$ ratio at $1.25 \times 10^{-3} \mathrm{M}$, the bioactive PAs were shown to support optimal adhesion, maximal proliferation, and prolonged viability of human corneal stromal fibroblasts (hCSFs), while improving the cell phenotype. These PAs also provided stable adhesive coatings on highly-hydrophobic surfaces composed of striated polytetrafluoroethylene (PTFE), significantly enhancing proliferation of aligned cells and increasing the complexity of the produced tissue. The thickness and structure of this highly-organised tissue were similar to those observed in vivo, comprising aligned newly-deposited extracellular matrix. As such, the developed coatings can constitute a versatile biomaterial for applications in cell biology, tissue engineering, and regenerative medicine requiring serum-free conditions.

\section{Introduction}

It is well understood that the three-dimensional structure of tissues is essential for the maintenance of cellular function and the development of physiologically relevant structures, and that the extracellular matrix (ECM) provides the structural and organizational guides for this tissue development. ${ }^{1}$ While cells on rigid, planar surfaces can respond to the chemical and mechanical

${ }^{a}$ School of Chemistry, Food and Pharmacy, University of Reading, Whiteknights, Reading RG6 6UB, UK. E-mail: c.j.connon@reading.ac.uk, che.connon@gmail.com; Tel: +44 (0)1183787053

${ }^{b}$ Optics \& Metrology Group, Diamond Light Source Ltd, Harwell Science and Innovation Campus, Oxfordshire, OX11 ODE, UK

$\dagger$ Electronic supplementary information (ESI) available. See DOI: 10.1039/c3tb21031f

\$ R.M.G., V.C., I.W.H., and C.J.C. conceived and designed the experiments. R.M.G. and V.C. performed the experiments. V.C. and I.W.H. designed the peptide amphiphiles. I.W.H. suggested the PTFE alignment substrate. C.J.C. suggested structuring of aligned 3D tissue constructs from 2D templates. S.G.A. contributed to AFM measurements and analysis tools. R.M.G., V.C., I.W.H., and C.J.C. analysed the data. R.M.G., I.W.H., and C.J.C. wrote the paper. nature of the ex vivo culture system, they typically have little capacity to reproduce a tissue-specific ECM. Furthermore, and unlike cultures in three-dimensional (3D) matrices, cells on flat, non-functionalized surfaces do not exhibit native phenotypes, which consequently affects their ability to form higher order structures. $^{2,3}$ Therefore, a biomaterial through which one can translate sophisticated two-dimensional (2D) experimental design into complex cell-derived 3D structures is of great value to both basic scientists and industry researchers. Such an approach may advance the understanding of tissue biology and disease progression as well as offer a solution to the existing paradox that cells can be grown quickly and easily on 2D substrates but lack the necessary hierarchical structure and phenotype to be used therapeutically as tissue engineered constructs.

From a biological point of view, materials used in tissue engineering should emulate the biochemical and biomechanical properties of the target tissue to be fully biocompatible. With this perspective, synthetic $2 \mathrm{D}$ cell support surfaces have been developed that contain components from, or inspired by, the biological ECM. ${ }^{\mathbf{1 , 4}}$ The tripeptide Arg-Gly-Asp is the 
ECM-derived motif most frequently used for creating adhesive biomaterials. ${ }^{5}$ Naturally occurring in many cell adhesion molecules, this sequence and the longer Arg-Gly-Asp-Ser tetrapeptide have been incorporated into a variety of synthetic materials to promote cell interaction and adhesion through binding to integrin subgroups, like those composed of subunits $\alpha \mathrm{V}, \alpha 3 \beta 1$, and $\alpha 5 \beta 1 .^{6,7}$ However, recent studies have shown that cells recognize synthetic peptide epitopes on artificial biomimetic surfaces only when arranged in defined patterns at the nanoscale, as the accessibility of adhesive epitopes may be impaired due to steric hindrance of flat synthetic surfaces. ${ }^{8}$

To address this issue, small adhesive peptides have been synthesized as self-assembling molecules to obtain supramolecular structures with geometrically-defined nanoscale patterns at distinct surface densities, which can be significantly higher than those achieved with intact matrix macromolecules. $^{9,10}$ The use of supramolecular self-assembly offers the possibility to control the structure, topography, shape, and dimensions of the biomaterial, as well as the spatial display and density of the bioactive motifs. This is made possible by the local order in the assembled nanostructures. ${ }^{9,11}$ Several classes of self-assembling biomaterials have been developed, including a class of synthetic peptide amphiphiles (PAs). Previously, PA nanostructures have been used for several biological applications. In particular, the Arg-Gly-Asp motif has been incorporated into PAs using various covalent architectures including linear, branched, and cyclic epitope presentations. ${ }^{7,12,13}$

In the present work, two synthetic PAs containing bioactive motifs, the $\mathrm{C}_{16} \mathrm{G}_{3}$ RGD (RGD) and $\mathrm{C}_{16} \mathrm{G}_{3}$ RGDS (RGDS), were designed and tested as biocompatible film coatings to enhance adhesion, proliferation, and alignment of human corneal stromal fibroblasts while inducing the formation of 3D lamellar-like stromal tissue in the absence of serum. These PAs constitute a simple, stable, and versatile system to bio-functionalize a variety of $2 \mathrm{D}$ surfaces capable of patterning specific cellular behaviour, thus leading to the novel formation of a highly-organized and phenotypically adequate $3 \mathrm{D}$ tissue in xeno-free conditions.

\section{Materials and methods}

\subsection{Preparation of peptide amphiphile (PA) surfaces}

PAs studied in this work (Fig. 1a) were custom-synthesized by CS Bio (Menlo Park, USA) as $>95 \%$ pure trifluoroacetic acid (TFA) salts, and their molecular weight was confirmed by electrospray-mass spectrometry. PAs $\mathrm{C}_{16} \mathrm{G}_{3} \mathrm{RGD}$ (RGD), $\mathrm{C}_{16} \mathrm{G}_{3}$ RGDS (RGDS), and $\mathrm{C}_{16}$ ETTES (ETTES, Glu-Thr-Thr-GluSer) were dissolved as single or binary component solutions in ultrapure water from a Barnstead Nanopure system to the desired concentration. To produce single system coatings, RGD and RGDS were dissolved at 5.4 and $3.0 \mathrm{wt} \%$, which corresponded to 7.0 and $3.6 \times 10^{-2} \mathrm{M}$, respectively, and spreadcoated onto standard polystyrene culture plates (Nunc, Thermo Scientific, USA). For the single and binary system films, the lyophilized RGD or RGDS was mixed with ETTES at various molar ratios and dissolved in water at a final concentration of $1 \times 10^{-5}$ to $10^{-2} \mathrm{M}$. The use of ETTES as a PA diluent was based

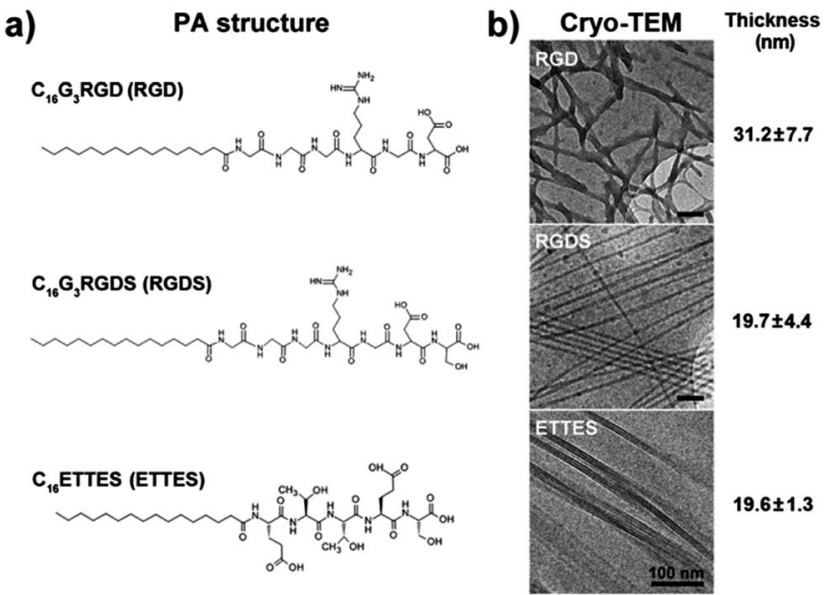

Fig. 1 Structure of peptide amphiphiles (PAs). (a) Molecular structure of $\mathrm{C}_{16} \mathrm{G}_{3} R G D$ (RGD), $\mathrm{C}_{16} \mathrm{G}_{3}$ RGDS (RGDS), and $\mathrm{C}_{16}$ ETTES (ETTES) PAs. (b) Conformation and average thickness (mean \pm S.D., $n=20$ ) of self-assembled PA nanostructures by cryo-TEM. Scale bars $=100 \mathrm{~nm}$.

on its anticipated lack of bio-adhesive activity. To produce thin dry film coatings, $100 \mu \mathrm{L}$ aliquots from PA solutions were spotted as $\approx 1.5 \mathrm{~cm}^{2}$ drops onto the different surfaces and left to dry overnight at room temperature inside an aseptic Class II cell culture cabinet. The resulting films were washed three times with sterile phosphate buffer saline (PBS) just prior to cell seeding. Stability of PAs was assessed by imaging film coatings upon drying and after incubation in serum-free culture media at $37{ }^{\circ} \mathrm{C}$ for seven days, using an inverted light microscope coupled with a Jenoptik CCD camera.

\subsection{Cryogenic transmission electron microscopy (Cryo- TEM)}

RGD, RGDS, and ETTES solutions at $1 \mathrm{wt} \%$ (corresponding to $1.3,1.2$, and $1.2 \times 10^{-2} \mathrm{M}$, respectively) were analysed by CryoTEM at Unilever Research, Colworth (Bedford, UK). PA drops $(3 \mu \mathrm{L})$ were placed on 400-mesh copper TEM grids (Elektron Technology, UK) covered with a perforated carbon film (plasma treated), automatically blotted, plunged into liquid ethane $\left(-183^{\circ} \mathrm{C}\right)$ to form a vitrified specimen, and transferred to liquid nitrogen $\left(-196{ }^{\circ} \mathrm{C}\right)$ for storage. The specimen was examined under a JEM-2100 electron microscope (JEOL, Japan) at $200 \mathrm{kV}$, at temperatures below $-175^{\circ} \mathrm{C}$. Images were recorded digitally on a Gatan UltraScan 1000 cooled CCD camera using DigitalMicrograph (Gatan, USA) in the low-dose imaging mode to minimize beam exposure and electron-beam radiation damage.

\subsection{Cell culture}

Human corneal stromal fibroblasts (hCSFs) were isolated from epithelia-depleted corneal rings from post-mortem human eyes, kindly provided by Mr Martin Leyland, M.D. (Royal Berkshire Hospital, Reading, UK). Briefly, the tissue was shredded using a scalpel, transferred to Dulbecco's Modified Eagle Medium (DMEM) supplemented with $2 \mathrm{~g} \mathrm{~L}^{-1}$ of collagenase type-I (Invitrogen, USA) and 5\% FBS, and incubated under rotation for 
5 hours at $37{ }^{\circ} \mathrm{C}$, followed by incubation with $0.25 \%$ trypsinEDTA in DMEM medium for 10 minutes. Isolated hCSFs were plated onto standard polystyrene culture plates (Nunc) and maintained in DMEM/F12 media (Invitrogen) supplemented with $5 \%$ FBS, $1 \times 10^{-3} \mathrm{M}$ ascorbic acid, and 1\% penicillin/ streptomycin. Media were replaced every 2-3 days. Upon reaching $70-80 \%$ confluence, cells were passaged and transferred to serum-free media three days prior to subsequent experiments in order to inactivate hCSFs. Cells were seeded onto the various PA coatings at $1.5 \times 10^{4}$ cells per $\mathrm{cm}^{2}$ in serumfree culture media.

\subsection{Biocompatibility and bioactivity assays}

To evaluate the biocompatibility and bioactivity of RGD(S), thin PA film coatings were seeded with hCSFs, and cell proliferation was evaluated using the AlamarBlue assay (Invitrogen) according to the manufacturer's instructions. Briefly, cell media were replaced $24 \mathrm{~h}$ post-seeding with resazurin reagent (diluted $1: 10$ in culture medium). After incubating for $4 \mathrm{~h}$ at $37^{\circ} \mathrm{C}$, resazurin was removed and sampled (100 $\mu \mathrm{L}$, in triplicate) for fluorescence emission at $590 \mathrm{~nm}$, and cells replenished with fresh culture media. The process was repeated each day for up to five days. The cell number was calculated by interpolation using a standard curve for the fluorescence values of 1, 5, 10, 20, 50, and $100 \times 10^{3}$ cells. Water-treated glass or polystyrene surfaces were used as the corresponding uncoated controls. All experiments were performed in triplicate.

\subsection{Adhesion specificity assays}

To assess the specificity of $\operatorname{RGD}(S)$ bioactivity, PA films were produced to coat ultra-low attachment tissue culture plates (Corning, USA) and seeded with hCSFs. Specific adhesion was quantified by counting attached cells using the AlamarBlue assay $24 \mathrm{~h}$ post-seeding. Human fibronectin (1918-FN-02M, R\&D Systems, USA) $100 \mu \mathrm{L}$ drops at $1 \times 10^{-4} \mathrm{M}$ and water were used as positive and negative coating controls, respectively. For the adhesion inhibition assay, hCSFs were passaged by thorough washing with sterile PBS followed by mechanical dislodging, transferred to $0.5 \mathrm{~mL}$ culture media supplemented with $50 \mu \mathrm{M}$ of solubilized RGD PA, cyclo[Arg-Gly-Asp(D-Phe)NMe-Val] (cyclic RGD, CS Bio) or anti-alphaV-integrin antibody (ab16821, Abcam, UK) (integrin blockers), or solubilized ETTES and anti-mouse IgG-HRP antibody (HAF007, R\&D Systems) (mock treatment), and incubated for 30 minutes at room temperature. After $5 \mathrm{~min}$ centrifugation at $500 \times g$, cells were resuspended, counted, and seeded onto PA films coating the surface of ultra-low attachment tissue culture plates.

\subsection{Cell migration assays}

Cells were cultured on PA films prepared from $1.25 \times 10^{-3} \mathrm{M}$ RGDS-ETTES solution at $13: 87\left(\mathrm{~mol} \mathrm{~mol}^{-1}\right)$ ratio on standard polystyrene culture plates. Water-treated polystyrene surfaces were used as the uncoated controls. Cell attachment was confirmed $6 \mathrm{~h}$ post-seeding, and migration behaviour during the following $24 \mathrm{~h}$ was observed using the LumaScope camera system (Etaluma, USA) with a 1 min time-lapse interval. Image sequences were then binarised and the movement of at least 100 cells per coating condition was quantified using the standard parameters of the wrMTrck plugin for ImageJ v1.3. All experiments were performed in triplicate.

\subsection{Expression of hCSF markers}

Cells growing for 21 days on uncoated or RGDS-ETTES $(1.25 \times$ $10^{-3} \mathrm{M}$ at $13: 87$ ratio)-coated standard polystyrene culture plates were harvested, and RNA was isolated by standard Trizol (Invitrogen) extraction. RNA quality was assessed using a NanoDrop 2000 spectrophotometer (Thermo Scientific, USA) to ensure the 260/280 ratio was within the range 1.7-2.0. Synthesis of cDNA from isolated total RNA was performed using the Maxima First cDNA Synthesis kit (Thermo Scientific) according to the manufacturer's instructions, in a TcPlus thermocycler (Techne, UK). Quantitative PCR (qPCR) was performed using the default thermal profile of the Eco Real-Time PCR System (Illumina, USA), with the following $40 \times$ three-step cycle: $10 \mathrm{~s}$ denaturation, $95{ }^{\circ} \mathrm{C}$; $30 \mathrm{~s}$ annealing, $60{ }^{\circ} \mathrm{C}$; and $15 \mathrm{~s}$ elongation, $72{ }^{\circ} \mathrm{C}$. The relative expression of genes coding for keratocan, lumican, decorin, and $\alpha$-smooth muscle actin ( $\alpha \mathrm{SMA}$ ) (primers against KERA, fwd.: TATTCCTGGAAGGCAAGGTG, rev.: ACCTGCC TCACACTTCTAGACC; LUM, fwd.: CCTGGTTGAGCTGGATCTGT, rev.: TAGGATAATGGCCCCAGGA; DCN, fwd.: GGCAAATTCCCG GATTAAA, rev. CAGGAAACTTGTGCAAGCAG; and ACTA2, fwd.: CTGAGCGTGGCTATTCCTTC, rev.: TTCTCAAGGGAGGATGAGGA, respectively) was analysed in duplicate, calculated by the comparative threshold cycle (CT) (Eco Software v3.1, Illumina) and normalized to the expression of the RNA polymerase II subunit RPB1 (POLR2A) housekeeping gene (fwd.: CATCATCCGAGA CAATGGTG, rev.: AACAATGTCCCCATCACACA) in three independent experiments. Expression of keratocan, lumican, and decorin proteoglycans, as well as $\alpha$ SMA of hCSFs, after 21 days in culture was analysed from cell lysates using ice-cold RIPA lysis buffer supplemented with Protease Inhibitors Cocktail (Roche, $\mathrm{CH}$ ) for $10 \mathrm{~min}$. After precipitation with $4 \times$ volumes of ethanol and pellet resuspension in sample buffer, lysates were run by SDSPAGE using 10\% Mini-Protean precast gels (Bio-Rad, USA) and blotted into PVDF (Thermo-Fisher). Membranes were then blocked in PBS supplemented with 5\% BSA and 0.1\% Tween 20, and incubated with primary antibodies against keratocan, lumican (sc-66941 and sc-166871, respectively, Santa Cruz Biotechnology), decorin (PC673, CalBiochem, Millipore), and aSMA (VP-S281, Vector Labs, UK) diluted $1: 500$ in blocking solution, followed by addition of corresponding HRP-conjugated secondary antibodies. Mouse anti-GAPDH antibody (ab9484, Abcam) was used for protein normalization. Results were expressed as normalized values relative to the expression of cells grown on uncoated polystyrene surfaces from three independent experiments.

\subsection{Orientation assays}

Glass slides coated with oriented stripes of polytetrafluoroethylene (PTFE) were prepared as described elsewhere. ${ }^{14}$ PTFE slides were further coated with RGDS:ETTES PA solution $\left(1.25 \times 10^{-3} \mathrm{M}\right.$ at $13: 87$ ratio) $(\mathrm{PTFE}+\mathrm{PA})$. The resulting 
singly- or doubly-coated glass slides were imaged using an atomic force microscope (AFM) (DualScope, DME, DK) in noncontact "tapping" mode over randomly selected $60 \times 60 \mu \mathrm{m}$ regions. Topography data were processed for line-wise and tilt correction using the Scanning Probe Image Processor (SPIP) software package. Coated slides were divided with Flexiperm chambers (Sarstedt, DE), into which hCSFs were seeded and cultured in serum-free media. Cells were quantified on the first and every other day thereafter using the AlamarBlue assay, and imaged to assess cell orientation using a phase-contrast inverted microscope. The uncoated glass surface on the rim of the slide was used as a cell adhesion and orientation control. At day 12, cells were fixed in $4 \%$ paraformaldehyde for $20 \mathrm{~min}$, washed twice with PBS for 5 min, blocked for $1 \mathrm{~h}$ in PBS supplemented with $2 \%$ goat serum and $2 \%$ BSA, exposed to $\alpha$-tubulin antibody (T6793, Sigma-Aldrich) in blocking solution (1: 1000) for $2 \mathrm{~h}$, washed thrice with PBS for $5 \mathrm{~min}$, and incubated with 1:1000 Alexa 594-conjugated phalloidin (A12381, Invitrogen) and goat anti-mouse IgG1 conjugated to Alexa 488 (A11001, Invitrogen) for an additional hour. Cells were mounted in Vectashield mounting media containing $4^{\prime}$,6diamidino-2-phenylindole (DAPI) (Vector Labs) to label cell nuclei and imaged using an Axio upright epifluorescence microscope (Zeiss, DE) coupled with a digital video camera (CoolSnap, RS Photometrics, USA). Tissues grown for 21 days were incubated with rabbit anti-collagen type I antibody (ab292, Abcam) and Alexa 488-conjugated phalloidin (A12379, Invitrogen) and imaged using a SP2 confocal microscope (Leica, Germany). Micrographs were analysed using the OrientationJ plugin from ImageJ v1.3 for automated orientation measurements and distribution. ${ }^{15}$ The angle of attached cells and their nuclei and cytoskeleton elements was calculated relative to the direction of the PTFE stripes and pooled in $5^{\circ}$ angle bins between $-90^{\circ}$ and $90^{\circ}$, with $0^{\circ}$ being parallel to the stripes and $90^{\circ}$ being perpendicular. Negative and positive values indicated the handedness of orientation with respect to the stripe orientation axis.

\subsection{Scanning electron microscopy (SEM)}

To evaluate the orientation of deposited collagen, cells on PTFE, PTFE + PA, and uncoated glass surfaces were cultured for 21 days and analysed by scanning electron microscopy (SEM). Slides were fixed with $2.5 \%$ glutaraldehyde for $20 \mathrm{~min}$ and osmium tetroxide for $60 \mathrm{~min}$ at r.t., and then dehydrated through a graded series of ethanol solutions $(25,50,70,90,100$, 100 , and $100 \%$ ) prior to critical point drying and gold sputter coating. SEM analysis was performed using a Quanta FEG 600 Environmental Scanning Electron Microscope (FEI, USA). The average fibril diameter was obtained from 100 individual collagen fibrils. The thickness of tissues formed on different surfaces was evaluated by imaging transversal cuts of slides with different coatings. Individual images were binarised, and the area occupied by tissue was calculated using ImageJ v1.3. The average thickness was obtained from 100 individual SEM images per coating condition by calculating the ratio between tissue area and length of the transversal field $(23.83 \mu \mathrm{m}$ constant). All experiments were performed in triplicate.

\subsection{Data analysis and statistics}

Error bars represent the standard deviation of the mean. Differences between groups were determined using one- or twoway analysis of variance (ANOVA) with Tukey's multiple comparison post hoc test. Distribution plots of orientation were analysed for independence using a $C h i$-square test. Significance between groups was established for $p<0.05,0.01$, and 0.001 .

\section{Results}

\subsection{Self-assembly of $\operatorname{RGD}(S)$ peptide amphiphiles}

Two PAs, $\mathrm{C}_{16} \mathrm{G}_{3} \mathrm{RGD}$ (RGD) and $\mathrm{C}_{16} \mathrm{G}_{3}$ RGDS (RGDS) (Fig. 1a), were tested as potential bioactive surfaces for in vitro culture of human corneal stromal fibroblasts (hCSFs). These PAs were able to self-assemble at low concentrations, and when imaged by cryo-TEM, RGD and RGDS in $1 \mathrm{wt} \%$ solutions they assumed strikingly different conformations (Fig. 1b). At this concentration, RGD and RGDS formed nanotape networks and twisted nanotapes, ${ }^{16}$ with widths of $31.2 \pm 7.7$ and $19.7 \pm 4.4 \mathrm{~nm}$, respectively (Fig. 1b). When drop-spotted and dried onto polystyrene surfaces, these PA solutions produced thin film coatings that remained stable under cell culture conditions (ESI Fig. $1 \dagger$ ).

\subsection{Biocompatibility of $\mathrm{RGD}(\mathrm{S})$}

When dissolved in water at 5.4 (RGD) and $3.0 \mathrm{wt} \%$ (RGDS), these PAs formed viscous solutions that were spread-coated onto cell culture polystyrene and tested for their properties as biocompatible cell adhesion and proliferation promoters. Surprisingly, hCSFs seeded onto these surfaces did not proliferate (Fig. 2a) and assumed a round morphology and adhered poorly, both constituting evident signs of cytotoxicity (Fig. 2b). Furthermore, after five days in culture no viable cells were found on these PA coatings, in contrast to those grown on uncoated polystyrene surfaces, which still maintained their characteristic fusiform morphology and proliferative capabilities (Fig. 2a and b). These results indicated that, at these concentrations, the PAs induced a toxic reaction in the cells, thus limiting cell adhesion and preventing subsequent proliferation.

As such, RGD and RGDS solutions at 0.005 to $1.0 \mathrm{wt} \%$ (corresponding to 6.5 and $6 \times 10^{-5}$ to 1.3 and $1.2 \times 10^{-2} \mathrm{M}$, respectively) were drop-spotted on top of the polystyrene surfaces and dried to obtain thin film coatings composed of RGD and RGDS nanotape aggregates. Water-treated polystyrene surfaces were used as an uncoated control. Cells seeded onto 0.005-0.1 wt\% PA films were shown to adhere strongly to the surface $24 \mathrm{~h}$ post-seeding (Fig. 2c). Cells growing on these films maintained high viability, achieving at day five maximum cell numbers on $0.1 \mathrm{wt} \% \mathrm{RGD}(\mathrm{S})$, which corresponded to a significant 1.2-fold increase in cell density compared to uncoated polystyrene ( $0 \mathrm{wt} \%)(p<0.01$; Fig. $2 \mathrm{c})$. These cells acquired a fusiform morphology with a substantial number of process extensions, which constituted an indication of viable cells with appropriate phenotype (Fig. 2b). However, RGD(S) films 
a)

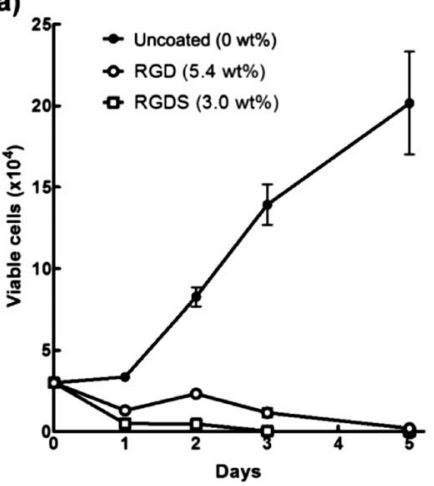

b)

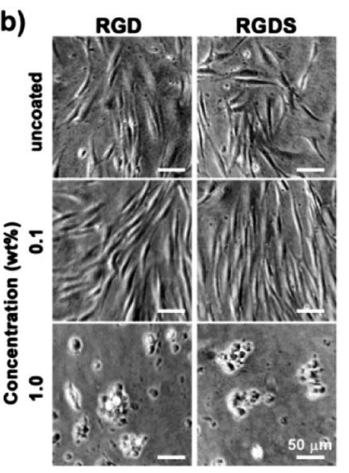

c)

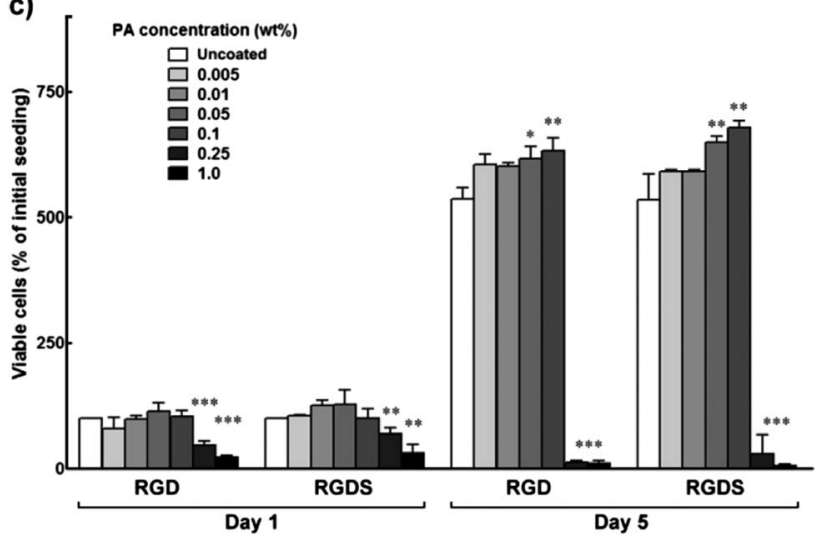

Fig. 2 Biocompatibility of RGD and RGDS PAs. (a) Proliferation of hCSFs grown for five days on 5.4 wt $\%$ RGD, 3 wt $\%$ RGDS, and polystyrene culture surfaces (uncoated control). (b) Phase-contrast micrographs of day 5 hCSFs grown on RGD and RGDS films produced from 0.1 and $1.0 \mathrm{wt} \%$ PA solutions, or uncoated polystyrene $(0 \mathrm{wt} \%)$. Scale bars $=50 \mu \mathrm{m}$. (c) Proliferation of hCSFs grown for five days on films produced from RGD and RGDS PA solutions at different concentrations (mean \pm S.D., $n=3$ for all experiments; $* * *$ and $* * *$ corresponded to $p<$ $0.05,0.01$, and 0.001 , respectively).

produced from 0.25 and $1.0 \mathrm{wt} \%$ solutions significantly impaired hCSF adhesion at day 1 ( $p<0.001$ and 0.01 , respectively; Fig. 2c) and induced cells to assume a round morphology similar to that previously observed for higher RGD(S) concentrations. Consequent cell proliferation was also significantly impaired, up to day 5 (Fig. 2c). Together, these results showed that $\mathrm{RGD}(\mathrm{S})$ PAs were able to self-assemble into organized nanotape structures that, when used as coatings up to $0.1 \mathrm{wt} \%$ (i.e., 1.3 and $1.2 \times 10^{-3} \mathrm{M}$, respectively), provided stable, biocompatible film substrates that promoted hCSF adhesion and proliferation.

\subsection{Optimization of RGD(S) bioactivity}

As single system PAs, RGD or RGDS nanotapes probably present highly-packed bioactive motifs at their surfaces, which could possibly impair epitope motion and accessibility. To modulate the density of the bioactive motifs, RGD(S) PAs were mixed with the negatively-charged, non-adhesive peptide amphiphile $\mathrm{C}_{16}$ ETTES (ETTES; Fig. 1a) at various molar ratios to create self-assembling, binary system nanostructures. ${ }^{16}$ Alone, ETTES also formed nanotape structures with widths of $19.6 \pm 1.3 \mathrm{~nm}$ (Fig. 1b). Mixed PA solutions were prepared at $1 \times 10^{-4}$ to $10^{-2} \mathrm{M}$ final concentrations and drop-spotted and dried onto low-attachment culture plates. These super-hydrophobic surfaces were used to increase the specificity of cell adhesion by restricting it to the $\operatorname{RGD}(\mathrm{S})$ coatings (Fig. 3a). Human fibronectin and water coatings were used on low-attachment surfaces as positive and negative controls, respectively. Results showed that, $24 \mathrm{~h}$ post seeding, hCSFs were attached to films containing RGD(S) molecules, but not to uncoated or ETTES-coated (ratio $0: 100$ ) surfaces (Fig. 3b). In addition, RGD(S) films produced from $1 \times 10^{-4}$ to $1.25 \times 10^{-3} \mathrm{M}$ solutions were able to maintain high cell viability and enhance proliferation for the entire period in culture. In addition, the effects on cell proliferation were shown to be dependent on PA concentration (ESI Fig. $2 \dagger$ ), with maximum cell numbers obtained at day five for the coatings produced from 13:87 molar ratio of RGD:ETTES and RGDS:ETTES at $1.25 \times 10^{-3} \mathrm{M}$. Proliferation on these coatings represented a significant 1.2- and 1.4-fold increase over the corresponding single (100:0 molar ratio) PA systems $(p<0.001$ and 0.01 , respectively; Fig. $3 \mathrm{~b}$ ), or 2.4 - and 2.8 -fold increase over fibronectin coatings (Fig. 3b). Beyond the $13: 87$ ratio, hCSF adhesion and proliferation decreased significantly. On the other hand, and as previously observed for films produced on polystyrene, PAs at $1 \times 10^{-2} \mathrm{M}$ impaired cell proliferation and compromised cell viability (ESI Fig. $2 \dagger$ ), indicating that higher concentrations of the $\mathrm{RGD}(\mathrm{S})$-PAs are toxic to cells.

\subsection{Specificity of $\operatorname{RGD}(S)$ bioactivity}

To verify the specificity of cell adhesion to the RGD(S) motifs, an inhibition assay was performed using soluble factors to block predominant integrins expressed at the surface of hCSFs (Fig. 3a). Integrins constitute a class of transmembrane receptors involved in the regulation of cell adhesion, shape, motility, and signalling. Cells were incubated with soluble RGD PA (+RGD), cyclic RGD (+cRGD), or anti- $\alpha \mathrm{V}$-integrin antibody $(+\mathrm{Ab})$ prior to seeding onto $1.25 \times 10^{-3} \mathrm{M} \operatorname{RGD}(\mathrm{S})$ :ETTES (13:87) or fibronectin-coated low-attachment surfaces, while soluble ETTES and anti-mouse IgG-HRP antibody were used as mock treatments (Fig. 3c). Water-treated low-attachment surfaces (uncoated) were used as negative controls. After $24 \mathrm{~h}$ of seeding, it was observed that the integrin-blocking treatments significantly reduced the number of hCSFs attached to either RGD:ETTES or RGDS:ETTES coatings to less than one third of that from mock treatments $(p<0.001$; Fig. 3c). The number of cells attached to fibronectin coatings was also significantly reduced by treatment with blockers to approximately half the number under mock conditions $(p<0.001$; Fig. 3c). As all experiments were performed without FBS, the effects observed were attributed to the direct contact between hCSFs and the PA coatings and not associated with any factor present in the serum. These results demonstrate that the enhanced cell adhesion observed for the RGD(S)-PA coatings is a specific effect, and involves the direct interaction between the adhesion motifs of RGD(S) and integrins, namely those containing the $\alpha \mathrm{V}$ subunit. 
a)

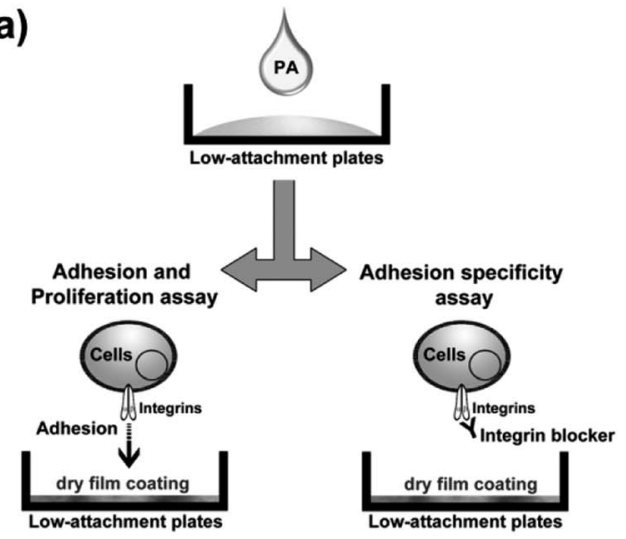

c)

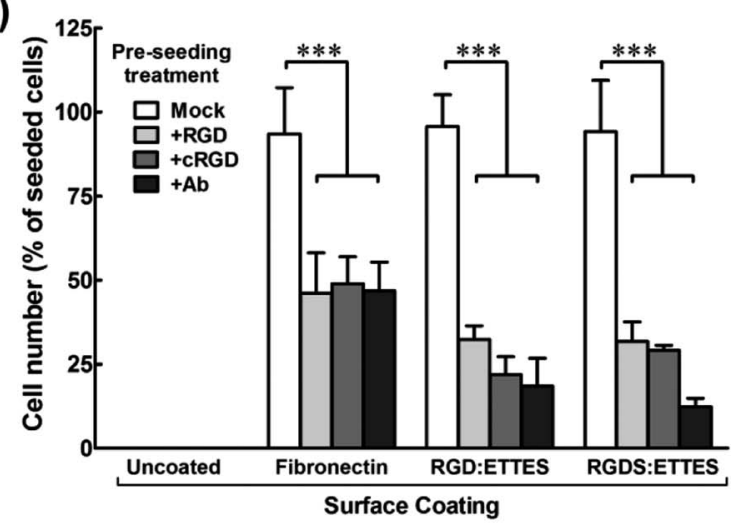

b)

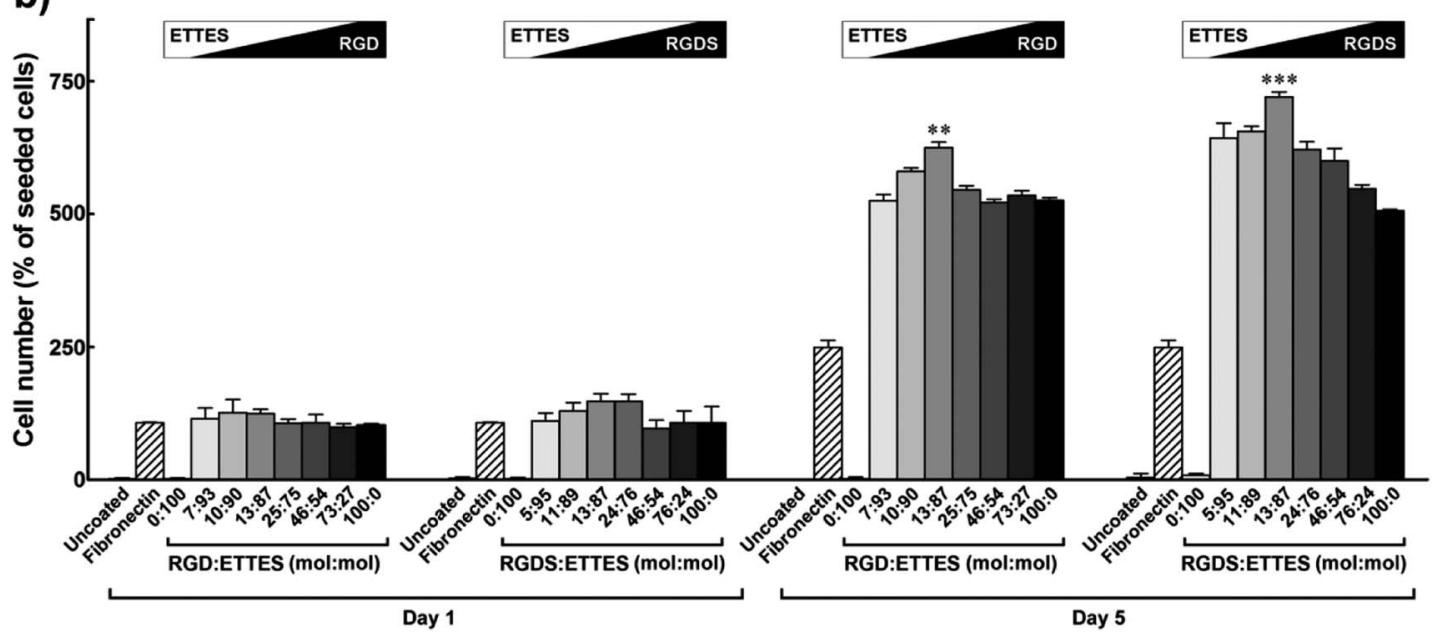

Fig. 3 Specific adhesion and optimized proliferation of hCSFs cultured on RGD(S) or RGD(S):ETTES films coating low-attachment plates. (a) Schematic diagram of PA film production and cell adhesion specificity assay. (b) Proliferation of hCSFs cultured for five days on binary PA films produced using $1.25 \times 10^{-3} \mathrm{M}$ PA solutions with different molar ratios of RGD(S) and ETTES. (c) Specificity of hCSF adhesion to RGD(S)-coated surfaces $\left(1.25 \times 10^{-3} \mathrm{M}\right.$ PA). Blocking of $\alpha \mathrm{V}$-integrins was performed prior to cell seeding using soluble PA (+RGD), cyclic RGD (+cRGD), or anti- $\alpha$-integrin antibody (+Ab). Fibronectin-coated and uncoated surfaces were used as positive and negative adhesion controls, respectively. All experiments were performed using low-attachment surfaces to maximize specificity of adhesion. Mean \pm S.D., $n=3$ for all experiments; ** and $* * *$ corresponded to $p<0.01$ and 0.001 , respectively.

\subsection{Effect of RGDS-PA on the hCSF phenotype}

As the bioactivity of $\mathrm{RGD}(\mathrm{S})$ depended on interaction with integrins responsible for ECM-intracellular communication and signalling, it was important to examine other possible effects of PA coatings on the hCSF phenotype. In this perspective, hCSFs seeded on the previously optimized RGDS:ETTES coating (13: 87 mol mol ${ }^{-1}$ ratio at $1.25 \times 10^{-3} \mathrm{M}$ ) were analysed by time-lapse microscopy and compared to cells on polystyrene (uncoated) (Fig. 4). Cells immediately attached to the PA surface, and developed a dendritic or stellate morphology with numerous cell processes $6 \mathrm{~h}$ after seeding $\left(T_{0}\right.$, Fig. $\left.4 \mathrm{a}\right)$. When tracked for $24 \mathrm{~h}$, hCSFs on PA-coated surfaces mostly maintained their original position $\left(T_{0-24}\right.$, Fig. 4a), moving at an average of $7.5 \pm 3.9 \mu \mathrm{m} \mathrm{h}^{-1}$ and with $20 \pm 5 \%$ of cells being immobile $\left(0 \mu \mathrm{m} \mathrm{h}^{-1}\right)$ (Fig. $\left.4 \mathrm{~b}\right)$. In contrast, cell attachment on uncoated cell culture polystyrene surfaces was delayed, as observed by the presence of roundshaped cells for the first $6 \mathrm{~h}$ after seeding ( $T_{0}$, Fig. $\left.4 \mathrm{a}\right)$. In addition, hCSFs on uncoated polystyrene surfaces were much more motile (average of $14.9 \pm 5.8 \mu \mathrm{m} \mathrm{h}^{-1}$ ) and changed their positions throughout the $24 \mathrm{~h}$ imaging period, with only $4 \pm 2 \%$ of immobile cells (Fig. $4 \mathrm{a}$ and b).

Furthermore, cells grown for 21 days on this PA coating were examined for their expression of certain target markers by reverse transcription quantitative polymerase chain reaction (qPCR) and immunoblotting and compared to cells on polystyrene (uncoated) (Fig. 5). Previous studies have shown that, when cultured in serum-free media, hCSFs revert to a characteristic $\alpha$ SMA-negative phenotype and express a defined panel of proteoglycan markers that include keratocan, lumican, and decorin, all of which are fundamental for the function of the native tissue. ${ }^{\mathbf{1 7 - 2 0}}$ Our results showed that the expression of keratocan, lumican and decorin transcripts significantly increased in hCSFs grown on PA-coated surfaces when compared to cells on uncoated polystyrene (Fig. 5a). Similarly, the total amount of these proteoglycans expressed in PA-supported cells was increased at least 2-fold when compared to uncoated polystyrene conditions (Fig. 5b). On the other hand, the PA coating did not up-regulate aSMA transcription 
a)

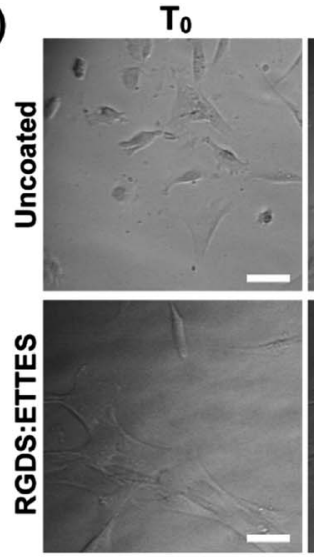

$T_{1}$
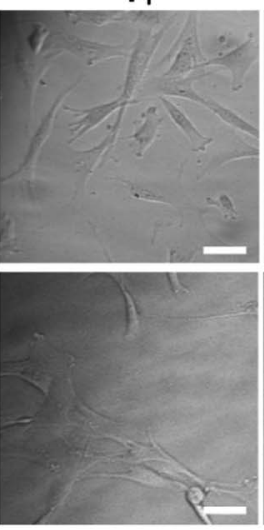

$T_{4}$

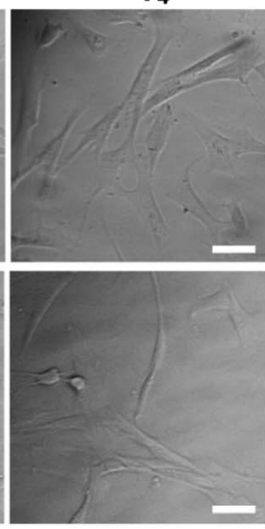

$\mathbf{T}_{24}$

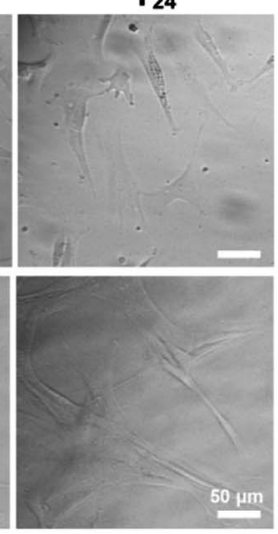

b)

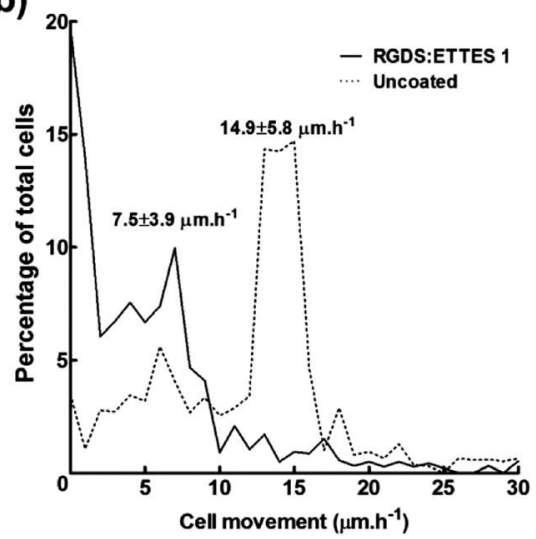

Fig. 4 Migration of hCSFs cultured on $1.25 \times 10^{-3}$ M RGDS:ETTES (13: 87 molar ratio)-coated polystyrene surfaces in serum-free medium. (a) Movement of cells and cell processes were monitored in 1 min lapse intervals between $6\left(T_{0}\right)$ and $30 \mathrm{~h}\left(T_{24}\right)$ post-seeding using bright-field microscopy. Uncoated polystyrene culture surfaces were used as a control. Scale bars $=50 \mu \mathrm{m}$. (b) Histogram of hCSF movement between $T_{0}$ and $T_{24}$, with average movement (mean \pm S.D.) of cells cultured on RGDS:ETTES-coated and uncoated polystyrene calculated from three independent experiments $(n=3)$.

a)
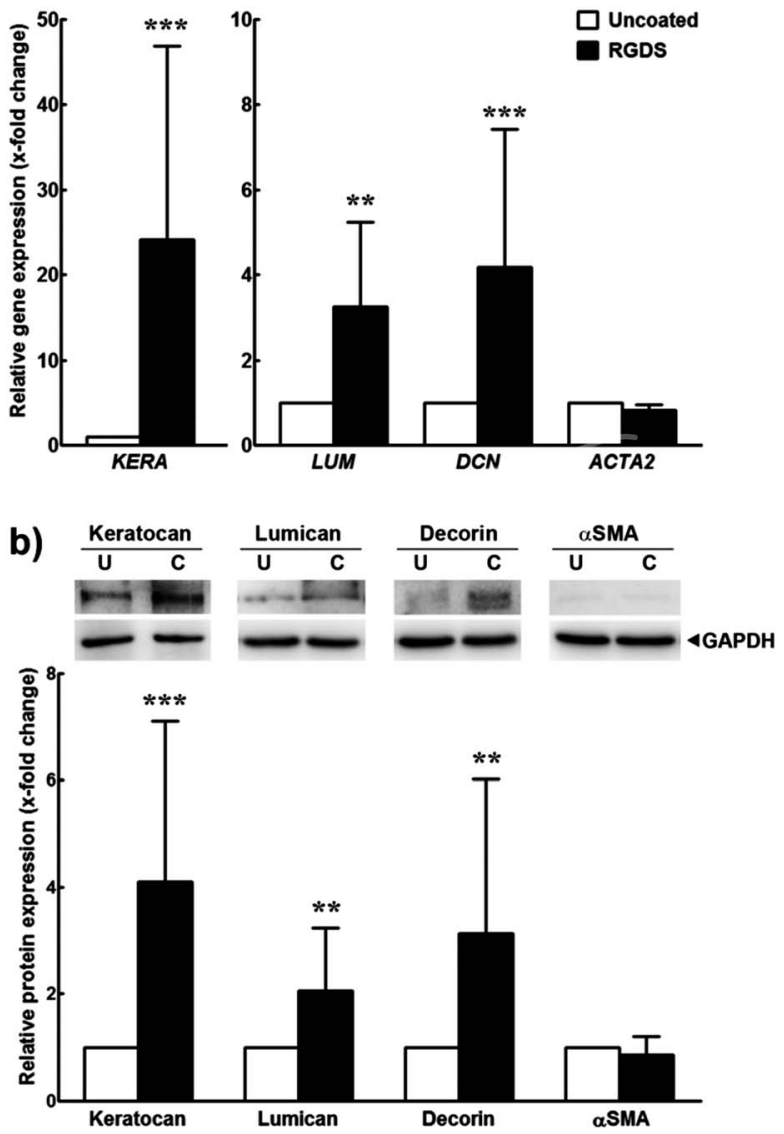

Fig. 5 Expression of markers from inactivated hCSFs grown on $1.25 \times 10^{-3} \mathrm{M}$ RGDS:ETTES (13:87 molar ratio)-coated polystyrene surfaces. Expression was analysed at the (a) transcriptional level by qPCR and (b) protein level by immunoblotting. Mean \pm S.D. values $(n=3)$ were normalized for expression of the POLR2A transcript or GAPDH protein, respectively, from cells grown on polystyrene culture surfaces (uncoated); ** and *** corresponded to $p<0.01$ and 0.001 , respectively. (corresponding to the expression of ACTA2) or protein levels. Taken together, these results indicated that the RGDS:ETTES coating not only increased cell adhesion and proliferation, but also enhanced the molecular and morphological phenotypes characteristic of hCSFs grown in serum-free conditions for long periods in culture.

\subsection{Effects of RGDS-PA on aligned hCSF cultures}

The use of PAs as a versatile culture substrate was further tested on glass slides coated with oriented stripes of polytetrafluoroethylene (PTFE), a highly-hydrophobic coating previously shown to induce cell alignment. ${ }^{\mathbf{1 4}}$ The RGDS:ETTES (13: 87) solution at $1.25 \times 10^{-3} \mathrm{M}$ was dropspotted over the oriented PTFE-coatings to produce the PA dry films (PTFE + PA; ESI Fig. $3 \dagger)$ and the different substrates were compared for hCSF adhesion and alignment (Fig. 6). Cells seeded onto the flat surface of the glass slides (uncoated, Fig. 6a) were evaluated as a control. Atomic force microscopy scans showed that PTFE was deposited with regular indentations of approximately $20 \mathrm{~nm}$ average depth (Fig. 6b). However, the PA film coating subsequently covered this aligned PTFE deposition and created an irregular topography comprising fibrillar PA nanotapes (Fig. 6b; ESI Fig. $3 \dagger$ ). The various coatings were cultured with hCSFs for 12 days, during which cells were quantified and imaged for predominant orientation. Results showed that all cells readily attached, reached confluence, and formed monolayers on the glass slides regardless of the surface coating. However, the RGDS:ETTES coatings allowed a significantly increased proliferation (Fig. 6c, day 5) and total cell density upon confluence when compared to PTFE-coated or uncoated surfaces, with a corresponding 1.2- and 1.6-fold increase in total cell number at day 12 (Fig. 6c). Differences in cell morphology were visible between PTFE- or PTFE + PA-coated and uncoated surfaces (Fig. 6d). In contrast to the multipolar, flat-spread morphology on the uncoated glass surfaces, hCSFs on coated surfaces became gradually more elongated and 
a)

b)

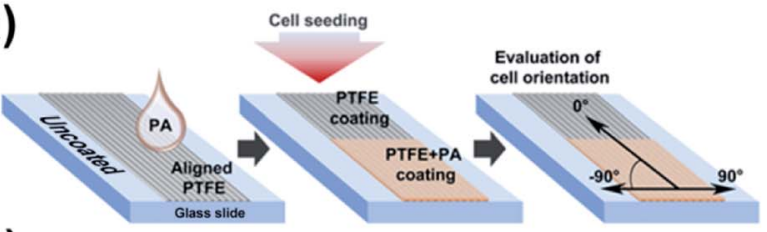

PTFE

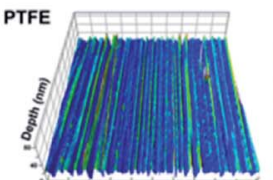

PTFE+PA

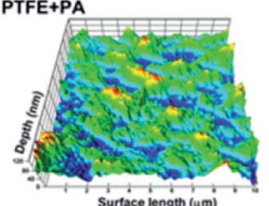

c)
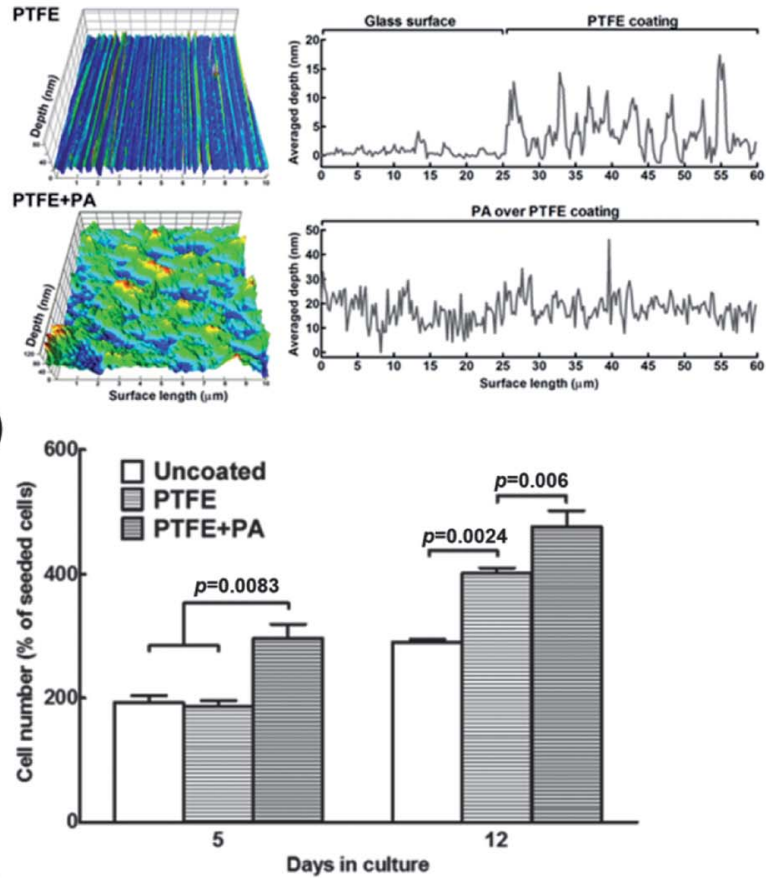

PA over PTFE coating

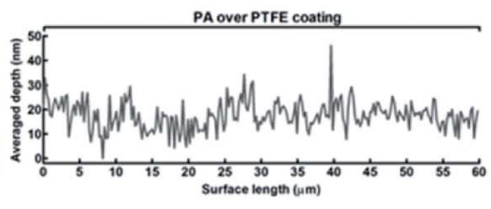

d)
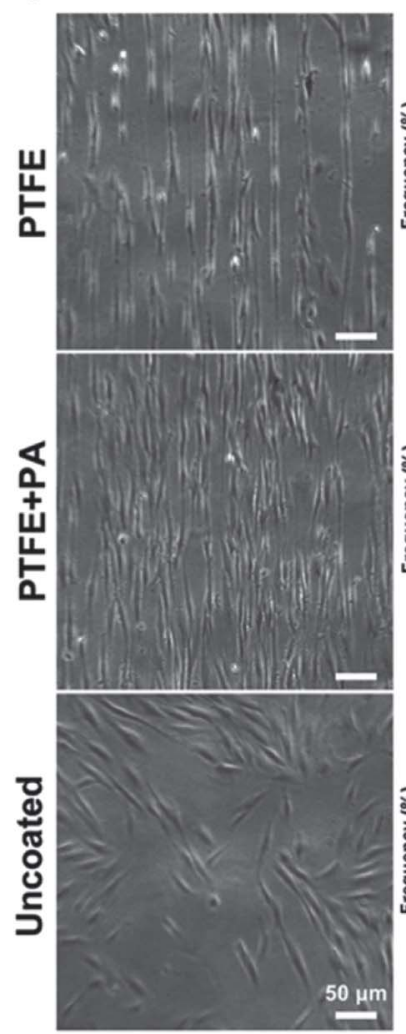

e)

Nucleus

F-Actin
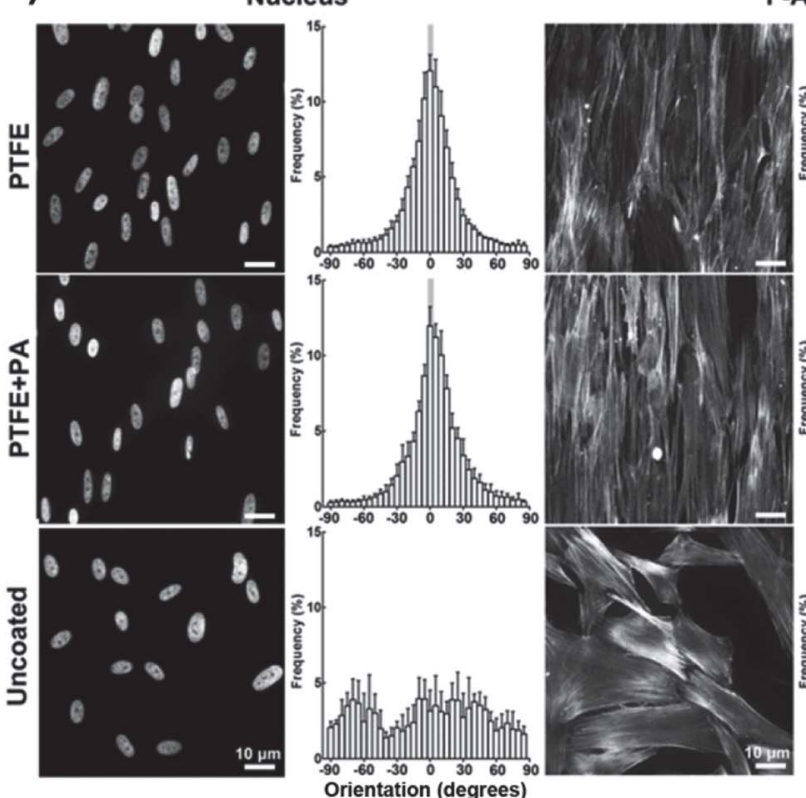

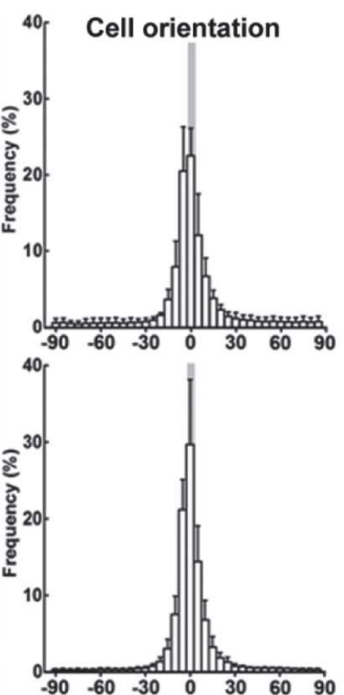

40

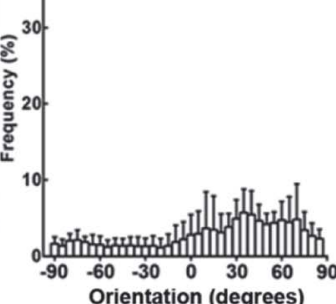

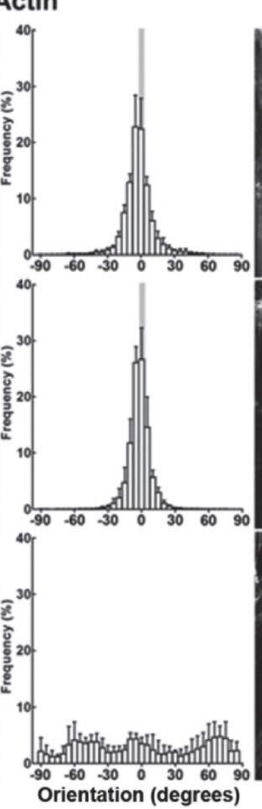

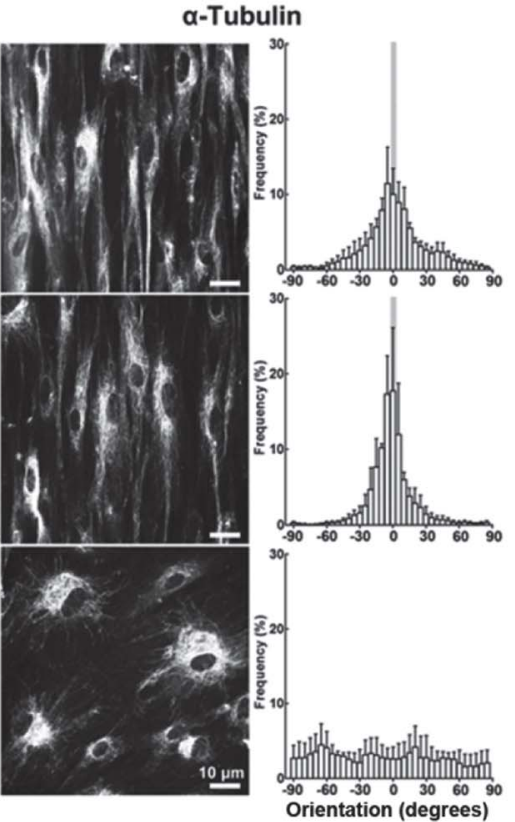

Fig. 6 Enhanced cell adhesion using $1.25 \times 10^{-3}$ M RGDS:ETTES (13: 87 molar ratio) coating (+PA) on alignment-inducing PTFE slides. (a) Schematic diagram of PTFE and PTFE + PA coatings. Uncoated glass was used as controls. (b) AFM mapping of PTFE and PTFE + PA coatings, with averaged $y$-value profiles corresponding to the coating depth. (c) Proliferation of hCSFs cultured at day 5 and 12 on different coatings. (d) Cell and corresponding (e) nucleus and cytoskeleton orientation of hCSFs cultured for 12 days on PTFE, PTFE + PA, and uncoated glass surfaces using phase-contrast and fluorescence microscopy, respectively. Mean \pm S.D., $n=3$ for all experiments. Scale bars $=$ (d) 50 and (e) $10 \mu \mathrm{m}$. 
assumed an orientation parallel to the PTFE stripes while maintaining many of their dendritic-like cell processes. This parallel orientation was maintained during the entire period in culture independently of the PA coating (Fig. 6d). In addition, significant differences in cell alignment were observed for PTFE- and PTFE-PA-coated surfaces compared to uncoated glass (Chi-square test for independence, $p<0.01, n=3$ ). At day $12,70 \pm 4$ (PTFE) and $80 \pm 4 \%$ (PTFE + PA) of hCSFs were oriented within $10^{\circ}$ of parallel, in contrast to the $14 \pm 3 \%$ of cells grown on uncoated glass (Fig. 6d).

The direct effect of the coatings on the spatial arrangement of the cell nuclei and of cytoskeletal proteins was examined by immunofluorescence microscopy. Results showed that the arrangement of the cytoskeleton reflected the overall morphology of the cell monolayers on the different surfaces (Fig. 6e). Low magnification observations of the cultured monolayers on the uncoated glass revealed small patches of similarly aligned neighbouring cells, which overall possessed a random orientation with respect to each other. In contrast, on the PTFE or PTFE + PA coated surfaces, an aligned cytoskeletal organization was maintained throughout the entire cell monolayer in the direction of the PTFE deposition. Quantitative analysis showed an isotropic cytoskeleton and nuclear organization in hCSFs on uncoated glass. In contrast, the cytoskeleton of hCSFs cultured on coated slides was aligned (Fig. 6e), with $77 \pm 3$ and $85 \pm 4 \%$ of actin microfilaments, and $46 \pm 3$ and $63 \pm 4 \%$ of $\alpha$-tubulin oriented within $10^{\circ}$ of the parallel in PTFE and PTFE + PA, respectively. Little or no bias was observed in the orientation of actin (18 \pm 2$)$ and $\alpha$-tubulin $(14 \pm 2 \%)$ on uncoated glass. Similar patterns were observed for the cell nucleus, as its ovoid shape on uncoated glass became more uniformly oriented in PTFE and PTFE + PA surfaces (Fig. 6e). Together, these results showed that the RGDS:ETTES coating enhanced adhesion, proliferation and alignment of hCSFs when compared to PTFE-coated or uncoated glass slides.

\subsection{Effects of RGDS-PA on the formation of aligned 3D tissue}

Cells cultured for a further 9 days (21 days in total) on PTFE or PTFE + PA coatings maintained their alignment while starting to grow on top of the original monolayer, i.e., stratification. The organization of the subsequently deposited collagenenriched ECM by the stratified cells was analysed using scanning electron microscopy (SEM). Cells grown for 21 days on PTFE or PTFE + PA showed highly-aligned deposits of collagen, with the longitudinal axes of the fibrils largely a)
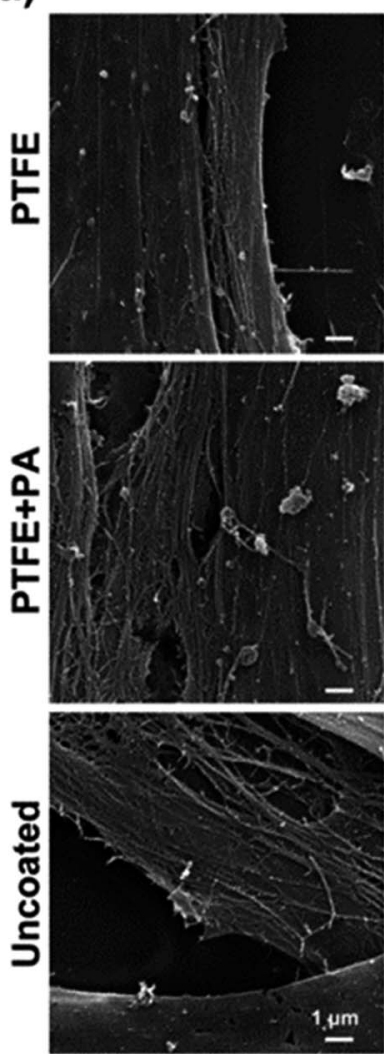

b)
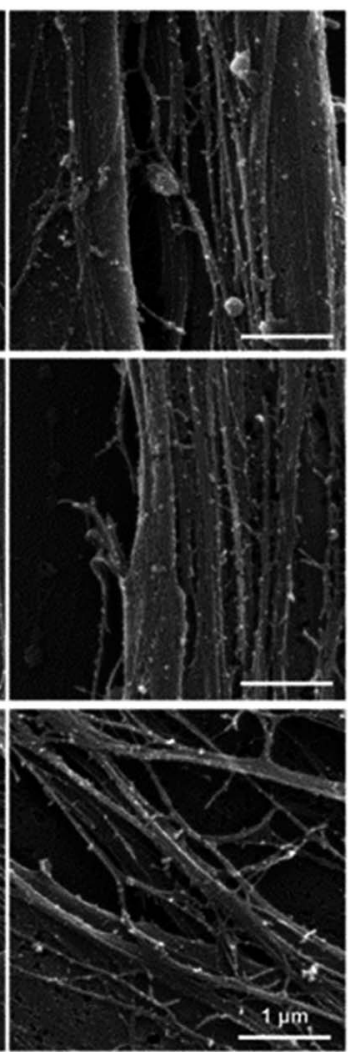
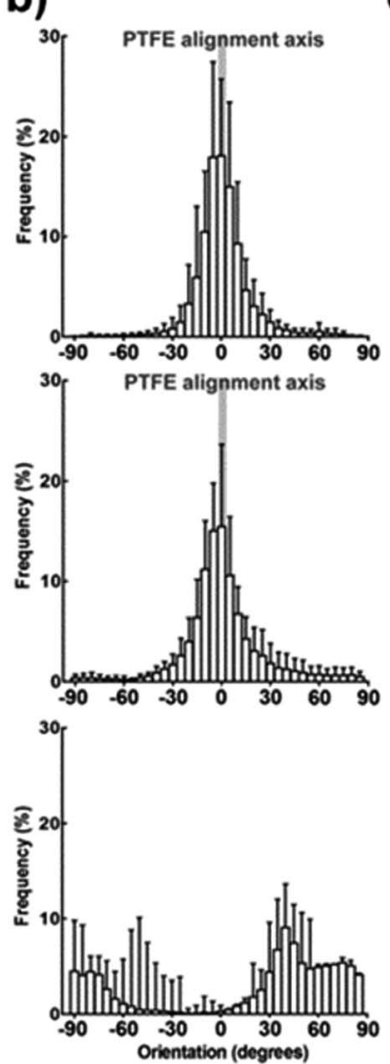

c)
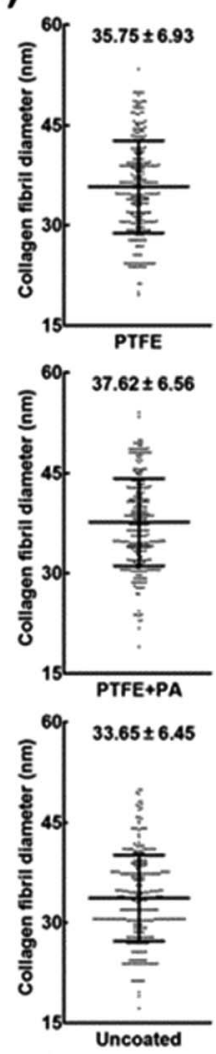

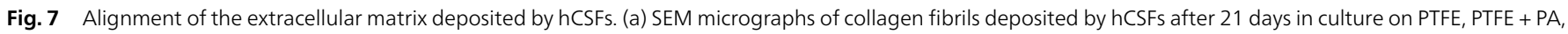

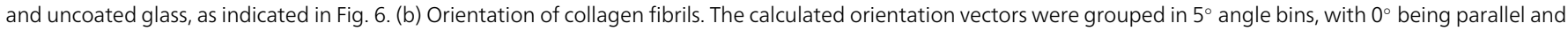

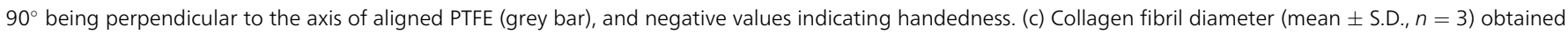
from 100 individual collagen fibrils from each of the three independent replicates. Scale bars $=1 \mu \mathrm{m}$. 
a)

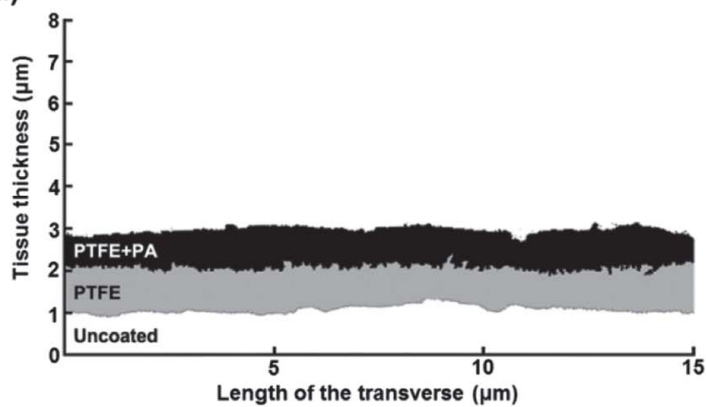

b)

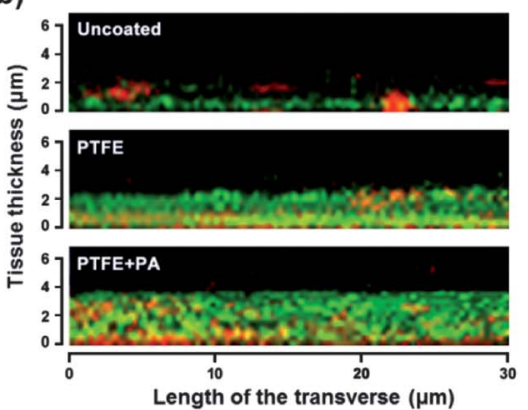

c)

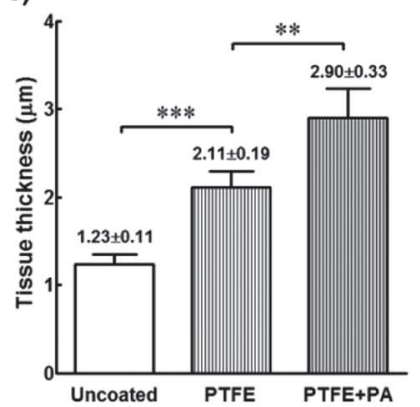

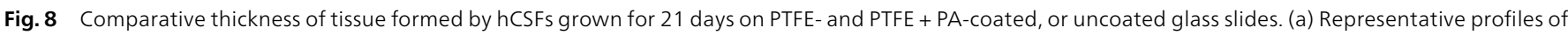

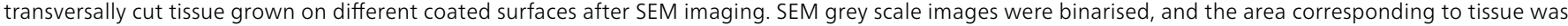

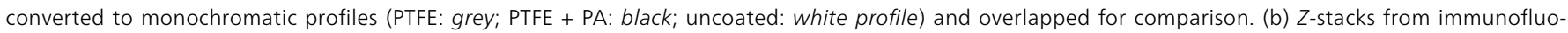

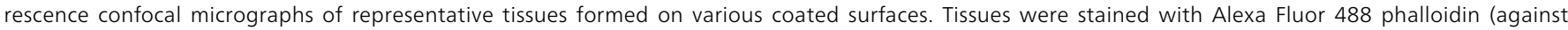

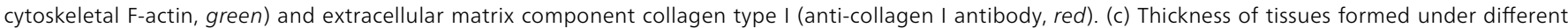

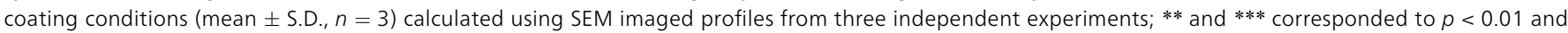
0.001 , respectively.

parallel to each other (Fig. 7a; ESI Fig. $4 \dagger$ ). In addition, there were numerous side branches that crosslink the collagen fibrils into an integrated ECM construct. Similarly to the alignment observed for cells in a monolayer, $71 \pm 8$ and $69 \pm$ $5 \%$ of the fibrils were oriented within $10^{\circ}$ of the axis in PTFE and PTFE + PA, respectively (Fig. 7b). This constituted a significantly lower range of distribution in fibril orientation when compared to uncoated surfaces, where collagen fibrils were found randomly oriented both at the cell and tissue level (Fig. 7b), with only $2 \pm 1 \%$ of fibrils aligned along the axis. Collagen fibrils from the stratified and aligned cell cultures were also longer and denser, extending between neighbouring cells. In contrast, cells growing on uncoated substrates deposited shorter collagen fibrils that mostly extended from the cell surface to an adjacent area on the substrate rather than to neighbouring cells (ESI Fig. $4 \dagger$ ). This corresponded to a slight difference between the diameter of individual collagen fibrils deposited on PTFE- $(40.2 \pm 8.1)$ or PTFE + PA-coated $(43.2 \pm 8.0)$ and uncoated glass $(37.4 \pm 7.3 \mathrm{~nm})$. The thickness of the stratified tissues formed after 21 days on the different coatings was quantified by imaging fixed preparations transversally using SEM (Fig. 8). Representative transversal cuts of the tissues obtained by SEM (Fig. 8a) or $z$-stack views of confocal fluorescence microscopy (Fig. 8b) confirmed that PTFE and PTFE + PA coatings allowed stacking of cell layers, whereas hCSFs on uncoated glass remained as a monolayer. In addition, this analysis showed that the tissue formed on PTFE + PA $(2.90 \pm 0.33 \mu \mathrm{m})$ was significantly thicker than those on PTFE $(2.11 \pm 0.19 \mu \mathrm{m} ; p<0.01)$ or uncoated glass $(1.23 \pm 0.11$ $\mu \mathrm{m} ; p<0.001$ ), with a corresponding 1.4 - and 2.4-fold increase in average thickness (Fig. 8c). Taken together, these results indicate that RGDS:ETTES films can be applied to a highlyhydrophobic PTFE coating, allowing enhanced cell adhesion and proliferation, and maintaining cell viability for long culture periods while inducing cell and ECM alignment and creating a thicker, more complex $3 \mathrm{D}$-structured tissue in the absence of serum.

\section{Discussion}

\subsection{RGD and RGDS peptide amphiphiles as versatile bioactive coatings}

In the present work, two peptide amphiphile molecules, RGD and RGDS, were developed and tested as versatile, bioactive coatings both able to support cell adhesion and proliferation, and to induce hierarchical 3D tissue organization. In addition, the specific interactions mediated by their bioactive motifs allowed phenotypically enhanced hCSFs to be maintained for extended periods in culture, circumventing the need to add serum or growth factors to the media. These PAs comprised a hydrophobic alkyl segment capable of controlling self-assembly of the molecules into nanostructures through hydrophobic packing of lipid chains and hydrogen bonding. Lipids chains were covalently grafted to protein-binding and cell signalling peptide sequence motifs. The assembly of PA molecules into nanotape structures emulated the architecture of the ECM and by design allowed the bioactive motif to be presented on the surface as the alkyl tail is buried in the core of the nanostructure through hydrophobic collapse. Previous studies have shown that electrostatic screening of charged amino acids on PA molecules by electrolytes in physiological media triggers self-assembly into high aspect-ratio nanostructures that form networks at relatively low concentrations, on the order of $0.1-1 \mathrm{wt} \% .^{21,22}$

Here, RGD(S) PAs were used as thin dry films to coat different types of surfaces, and subsequently assayed for their biocompatibility and ability to enhance cell adhesion and proliferation. $\mathrm{RGD}(\mathrm{S})$ films up to $1.25 \times 10^{-3} \mathrm{M}$ were shown to promote concentration-dependent adhesion and proliferation of hCSFs when coating a variety of surfaces, such as cell-adhesive polystyrene and glass, or highly-hydrophobic low-attachment culture dishes specially designed to keep cells in suspension. $\mathrm{RGD}(\mathrm{S})$ bioactivity was also shown to be dependent on the interaction with the $\alpha \mathrm{V}$-integrin of hCSFs. Integrins are a family of $\alpha, \beta$-heterodimeric transmembrane receptors which have in common the capacity to interlace transmembrane ties between 
cell surface molecules or the ECM and the cytoskeleton, thus triggering intracellular signalling pathways. ${ }^{23}$ In particular, the integrin $\alpha \mathrm{V}$ subunit is a cell adhesion molecule that plays an important role in hCSF adhesion to the stromal ECM and consequent signalling in vivo. ${ }^{24,25}$ Integrin signalling is a stepwise process, involving integrin activation by ligand binding followed by engagement in transmembrane linkage to the cytoskeleton, integrin clustering, focal contact formation, and signal transduction. ${ }^{26}$ Integrins are also involved in the regulation of mitosis and cell proliferation through several signalling pathways. ${ }^{27,28}$ The results presented here show that cells attached almost immediately to RGDS PA coatings, developing an immobile, stellate morphology with numerous cell processes characteristic of hCSFs ${ }^{29}$ while expressing increased levels of the specific and functionally relevant proteoglycans keratocan, lumican, and decorin. ${ }^{18}$ This indicated that $\operatorname{RGD}(\mathrm{S})$ PAs constitute an improved biomimetic substrate for hCSF culture compared to the widely-used polystyrene surfaces, while providing a bioactive surface that supplanted the need for serum or exogenous growth factors.

However, film coatings produced from $0.25 \mathrm{wt} \%$ solutions (i.e., 3.25 and $3 \times 10^{-3} \mathrm{M}$ of RGD and RGDS, respectively) compromised hCSF viability and proliferation, indicating that higher concentrations of the RGD(S)-PAs were toxic to cells. On the other hand, the concentration at which $\operatorname{RGD}(\mathrm{S})$ showed maximum bioactivity coincided with the biocompatibility threshold of these PAs. This was a surprising finding, as the interactions between surface-attached $\mathrm{RGD}(\mathrm{S})$ epitopes and integrins, particularly with the $\alpha \mathrm{V} \beta 3$ subtype, have been described as an anti-apoptotic mechanism in various cell types. ${ }^{30,31}$ Although the $\mathrm{RGD}(\mathrm{S})$ films produced in this study were shown to be stable and remained macroscopically intact, it is possible that a small percentage of PA molecules from highdensity coatings still dissolved into the cell media, thus releasing a solubilized, pro-apoptotic form of $\operatorname{RGD}(\mathrm{S})$. This hypothesis is supported by previous work showing that $1 \times 10^{-3}$ $\mathrm{M}$ of soluble Arg-Gly-Asp-containing linear peptides directly activate caspase-induced apoptosis and reduce proliferation of human lymphocytes ${ }^{32}$ and umbilical vein endothelial cells. ${ }^{33}$

Different PA molecules are capable of undergoing coassembly, allowing for a specific bioactive molecule to be mixed with a different bioactive molecule or a non-bioactive diluent molecule to vary the epitope density on the assembled nanostructure for optimized cell signalling. ${ }^{34-36} \mathrm{Here}$, the bioactivity of $\mathrm{RGD}(\mathrm{S})$ was optimized by creating binary PA systems, combining the negatively charged, non-adhesive peptide amphiphile ETTES with RGD or RGDS at various ratios to obtain mixed PA solutions. The increased bioactivity of RGD(S):ETTES PAs can most likely be attributed to a combination of factors, but most importantly to reduced epitope crowding and saturation avoidance, i.e., the epitope density beyond that which is optimal for cell adhesion. The optimal RGD(S) density obtained with $13: 87$ molar ratio probably represents a balanced $\operatorname{RGD}(\mathrm{S})$ motif packing, which then ensures sufficient spacing for epitope motion and accessibility, ${ }^{13,35}$ a crucial factor for fibroblast recognition and response. ${ }^{37}$ As the RGD(S) PAs incorporate a positively-charged arginine amino acid in the position corresponding to a negative charge on ETTES, an efficient co-assembly of stable binary nanostructures (i.e., composed by intercalated or interspersed PAs) is feasible. Our findings were also in agreement with previous studies showing that the biological effects of PA nanostructures carrying bioactive motifs were augmented when a negatively-charged PA was added to the system as a diluent. ${ }^{34-36}$ Together, these studies demonstrate the feasibility of integrating PAs comprising different peptide sequences into defined nanostructures. This raises the possibility of creating PA systems presenting multiple bioactive peptide motifs, for a more precise control of complex cellular responses.

\subsection{RGDS:ETTES 2D coating as an effector in the formation of 3D corneal stromal tissue}

As in many other tissue types, ${ }^{38}$ the function of the human corneal stroma depends inherently on the strict alignment of its constituent cells and ECM. ${ }^{19,39,40}$ Foams and meshes have been the leading scaffolds used as biomaterials to engineer the corneal stroma. ${ }^{41,42}$ However, in these systems structural changes that convert a scaffold into an artificial cornea must be accomplished by the hCSFs, without any physical cues to guide the secretion of newly synthetized ECM molecules. Incorporation of such cues into an artificial scaffold is important in the development of anisotropy (aligned collagen). Recently, the use of functionalized scaffolds to create multi-lamellar cornea constructs has been described. ${ }^{43}$ In this perspective, the use of the PAs developed in the present work to coat and functionalize scaffolds would constitute an advantage in terms of versatility. Alternatively, these PAs could be used to create 3D matrices able to encapsulate and maintain viable cells, as previously reported. ${ }^{44}$ Nonetheless, their application as $2 \mathrm{D}$ coatings greatly simplifies the culturing process and allows a greater degree of control over the culture conditions. Here, the cell-adhesive RGDS:ETTES PA was used on micro-rubbed PTFE glass slides, a highly-hydrophobic surface previously shown to induce cell alignment ${ }^{14}$ notwithstanding its capacity to reduce cell adhesion. ${ }^{45}$ Previous studies have shown that cells cultured on topographies with grooves less than $35 \mathrm{~nm}$ in depth are not aligned due to contact guidance. ${ }^{46-48}$ Considering that the grooves created by PTFE vary between $20 \mathrm{~nm}$ (this study) and 7-32 nm in depth, ${ }^{49}$ our results suggest that the alignment of hCSFs and their deposited ECM was not induced by surface topography. The RGDS:ETTES coating significantly enhanced adhesion and proliferation of highly-aligned hCSFs. But more importantly, and to our knowledge for the first time, the PA films allow the deposition of collagen fibrils to form a highlyorganized tissue with thickness, ECM structure, and average fibril diameter comparable to those found in stromal lamellae of the native human cornea. ${ }^{50,51}$

The increase in stratification due to PTFE-induced cell alignment was consistent with previous work on the effects of spatial guidance of corneal stromal stem cells. ${ }^{51}$ However, in the present work, we showed that the bioactive cues provided by the PA coating further increased the complexity of the formed tissue. When on RGDS:ETTES films, hCSFs produced aligned collagen fibrils that assembled both between and on top of cells 
in a multi-layered construct. Fibrils deposited on top were apparently derived from hCSFs not in direct contact with the RGDS-coated surface. In contrast, collagen fibrils deposited by hCSFs on uncoated glass were dispersed and limited to the planar surface. This suggests that hCSFs respond to the coated surface by inducing the cells growing on top of them to orient and produce aligned ECM. Furthermore, this tissue was formed by hCSFs during a period of 21 days in a serum-free media formulation comparable to that previously reported as insufficient to sustain viable bovine corneal fibroblast for more than 1.5 weeks in culture. ${ }^{52}$ This again indicated that the RGDS:ETTES coating functioned not only as a support for hCSF adhesion but also as an effector in tuning the cell phenotype and preventing cell death in serum-free conditions. This notion is supported by data showing that ligation of integrin $\alpha \mathrm{V} \beta 3$, a RGD receptor expressed by hCSFs, ${ }^{25}$ mediates cell survival after serum withdrawal. ${ }^{31}$ In the light of these results, we propose that hCSFs initially cultured in such a $2 \mathrm{D}$ system constitute, with the progression of culture, a viable substrate able to modulate the phenotype of overlaying cells, which in turn results in the formation of a 3D architecture and increased hierarchical complexity of the tissue. This is consistent with previous studies showing that the orientation, mechanical integrity, and architecture of the ECM influence cell migration and orientation by modifying the direction and composition of integrin adhesions, and vice versa..$^{53}$

\section{Conclusion}

In summary, this work showed that self-assembled nanostructures formed by co-assembly of $\operatorname{RGD}(\mathrm{S})$ and the negativelycharged ETTES diluent PA led to enhanced adhesion of cultured hCSFs that specifically employed the engagement of integrin containing the $\alpha \mathrm{V}$ subunit. Moreover, the binary RGD(S):ETTES nanostructures maintained viability and enhanced proliferation of hCSFs in vitro while improving the cell phenotype and avoiding the addition of serum or growth factors. We conclude that these PAs have the potential to overcome current limitations of common 2D tissue culture surfaces and conditions. The possibility to combine the PA systems with cell alignmentinducing substrates showed that the RGD(S)-PAs provide a feasible and versatile method for enhanced cell adhesion and modulation of in vitro tissue formation while circumventing the need to add serum to culture medium. A 2D system such as this allows the formation of stand-alone tissues prone to further processing, ${ }^{54}$ thus constituting a promising biomaterial to ensure increased cell adhesion and proliferation in prolonged periods in culture, and the growth of organized tissues with defined 3D architectures for cell biology, tissue engineering, and regenerative medicine applications.

\section{Acknowledgements}

We are grateful to the BBSRC (grants numbers BB/I008187/1 and BB/J019836/1) for financial support. We kindly acknowledge M. Leyland, Royal Berkshire Hospital for supplying the post-mortem corneal rings. We thank K. Feldman, Department of Materials, ETH Zürich for providing the PTFE-coated slides, and P. Harris and M. Spink, Centre for Advanced Microscopy of the University of Reading for technical assistance with SEM. We are grateful to S. Furzeland and D. Atkins, Unilever, Colworth, $\mathrm{UK}$, for technical assistance with cryo-TEM.

\section{Notes and references}

1 L. G. Griffith and M. A. Swartz, Nat. Rev. Mol. Cell Biol., 2006, 7, 211-224.

2 M. P. Lutolf, P. M. Gilbert and H. M. Blau, Nature, 2009, 462, 433-441.

3 M. D. Mager, V. LaPointe and M. M. Stevens, Nat. Chem., 2011, 3, 582-589.

4 E. S. Place, N. D. Evans and M. M. Stevens, Nat. Mater., 2009, 8, 457-470.

5 K. von der Mark and J. Park, Prog. Mater. Sci., 2013, 58, 327381.

6 V. Gribova, T. Crouzier and C. Picart, J. Mater. Chem., 2011, 21, 14354-14366.

7 U. Hersel, C. Dahmen and H. Kessler, Biomaterials, 2003, 24, 4385-4415.

8 E. A. Cavalcanti-Adam, D. Aydin, V. C. Hirschfeld-Warneken and J. P. Spatz, HFSP J., 2008, 2, 276-285.

9 I. W. Hamley, Soft Matter, 2011, 7, 4122-4138.

10 M. P. Lutolf and J. A. Hubbell, Nat. Biotechnol., 2005, 23, 4755.

11 J. D. Hartgerink, E. Beniash and S. I. Stupp, Science, 2001, 294, 1684-1688.

12 P. Sadatmousavi, M. Soltani, R. Nazarian, M. Jafari and P. Chen, Curr. Pharm. Biotechnol., 2011, 12, 1089-1100.

13 H. Storrie, M. O. Guler, S. N. Abu-Amara, T. Volberg, M. Rao, B. Geiger and S. I. Stupp, Biomaterials, 2007, 28, 4608-4618. 14 J. C. Wittmann and P. Smith, Nature, 1991, 352, 414-417.

15 R. Rezakhaniha, A. Agianniotis, J. T. Schrauwen, A. Griffa, D. Sage, C. V. Bouten, F. N. van de Vosse, M. Unser and N. Stergiopulos, Biomech. Model. Mechanobiol., 2012, 11, 461-473.

16 V. Castelletto, R. M. Gouveia, C. J. Connon and I. W. Hamley, Faraday Discuss., 2013, DOI: 10.1039/C3FD00064H.

17 C. J. Connon, V. Siegler, K. M. Meek, S. A. Hodson, B. Caterson, S. Kinoshita and A. J. Quantock, Ophthalmic Res., 2003, 35, 177-184.

18 W. W. Kao and C. Y. Liu, Glycoconjugate J., 2002, 19, 275-285. 19 A. J. Quantock and R. D. Young, Dev. Dyn., 2008, 237, 26072621.

20 L. Schaefer and R. V. Iozzo, J. Biol. Chem., 2008, 283, 2130521309.

21 E. Beniash, J. D. Hartgerink, H. Storrie, J. C. Stendahl and S. I. Stupp, Acta Biomater., 2005, 1, 387-397.

22 P. Palladino, V. Castelletto, A. Dehsorkhi, D. Stetsenko and I. W. Hamley, Langmuir, 2012, 28, 12209-12215.

23 S. H. Kim, J. Turnbull and S. Guimond, J. Endocrinol., 2011, 209, 139-151.

24 S. K. Masur, J. K. Cheung and S. Antohi, Invest. Ophthalmol. Visual Sci., 1993, 34, 2690-2698.

25 M. A. Stepp, Exp. Eye Res., 2006, 83, 3-15. 
26 M. Vicente-Manzanares, C. K. Choi and A. R. Horwitz, J. Cell Sci., 2009, 122, 199-206.

27 D. S. Harburger and D. A. Calderwood, J. Cell Sci., 2009, 122, 159-163.

28 B. Trappmann, J. E. Gautrot, J. T. Connelly, D. G. Strange, Y. Li, M. L. Oyen, M. A. Cohen Stuart, H. Boehm, B. Li, V. Vogel, J. P. Spatz, F. M. Watt and W. T. Huck, Nat. Mater., 2012, 11, 642-649.

29 J. V. Jester, P. A. Barry, G. J. Lind, W. M. Petroll, R. Garana and H. D. Cavanagh, Invest. Ophthalmol. Visual Sci., 1994, 35, 730-743.

30 V. Grigoriou, I. M. Shapiro, E. A. Cavalcanti-Adam, R. J. Composto, P. Ducheyne and C. S. Adams, J. Biol. Chem., 2005, 280, 1733-1739.

31 D. G. Stupack and D. A. Cheresh, J. Cell Sci., 2002, 115, 37293738.

32 C. D. Buckley, D. Pilling, N. V. Henriquez, G. Parsonage, K. Threlfall, D. Scheel-Toellner, D. L. Simmons, A. N. Akbar, J. M. Lord and M. Salmon, Nature, 1999, 397, 534-539.

33 M. S. Aguzzi, C. Giampietri, F. De Marchis, F. Padula, R. Gaeta, G. Ragone, M. C. Capogrossi and A. Facchiano, Blood, 2004, 103, 4180-4187.

34 J. Z. Gasiorowski and J. H. Collier, Biomacromolecules, 2011, 12, 3549-3558.

35 M. J. Webber, J. Tongers, M. A. Renault, J. G. Roncalli, D. W. Losordo and S. I. Stupp, Acta Biomater., 2010, 6, 3-11.

36 M. Zhou, A. M. Smith, A. K. Das, N. W. Hodson, R. F. Collins, R. V. Ulijn and J. E. Gough, Biomaterials, 2009, 30, 25232530.

37 G. Maheshwari, G. Brown, D. A. Lauffenburger, A. Wells and L. G. Griffith, J. Cell Sci., 2000, 113(Pt 10), 1677-1686.

38 W. Bian and N. Bursac, Biomaterials, 2009, 30, 1401-1412.

39 K. M. Meek and D. W. Leonard, Biophys. J., 1993, 64, 273280 .
40 K. M. Meek, D. W. Leonard, C. J. Connon, S. Dennis and S. Khan, Eye, 2003, 17, 927-936.

41 E. J. Orwin, M. L. Borene and A. Hubel, J. Biomech. Eng., 2003, 125, 439-444.

42 N. E. Vrana, N. Builles, V. Justin, J. Bednarz, G. Pellegrini, B. Ferrari, O. Damour, D. J. S. Hulmes and V. Hasirci, Invest. Ophthalmol. Visual Sci., 2008, 49, 5325-5331.

43 E. S. Gil, B. B. Mandal, S.-H. Park, J. K. Marchant, F. G. Omenetto and D. L. Kaplan, Biomaterials, 2010, 31, 8953-8963.

44 H. Cui, M. J. Webber and S. I. Stupp, Pept. Sci., 2010, 94, 118.

45 W. Song and J. F. Mano, Soft Matter, 2013, 9, 2985-2999.

46 W. A. Loesberg, J. te Riet, F. C. M. J. M. van Delft, P. Schön, C. G. Figdor, S. Speller, J. J. W. A. van Loon, X. F. Walboomers and J. A. Jansen, Biomaterials, 2007, 28, 3944-3951.

47 M. E. Manwaring, J. F. Walsh and P. A. Tresco, Biomaterials, 2004, 25, 3631-3638.

48 S. A. Pot, S. J. Liliensiek, K. E. Myrna, E. Bentley, J. V. Jester, P. F. Nealey and C. J. Murphy, Invest. Ophthalmol. Visual Sci., 2010, 51, 1373-1381.

49 P. Dietz, P. K. Hansma, K. J. Ihn, F. Motamedi and P. Smith, J. Mater. Sci., 1993, 28, 1372-1376.

50 J. W. Ruberti and J. D. Zieske, Prog. Retinal Eye Res., 2008, 27, 549-577.

51 J. Wu, Y. Du, S. C. Watkins, J. L. Funderburgh and W. R. Wagner, Biomaterials, 2012, 33, 1343-1352.

52 E. M. Bueno, N. Saeidi, S. Melotti and J. W. Ruberti, Tissue Eng., Part A, 2009, 15, 3559-3573.

53 J. J. Rice, M. M. Martino, L. De Laporte, F. Tortelli, P. S. Briquez and J. A. Hubbell, Adv. Healthcare Mater., 2013, 2, 57-71.

54 Y. Haraguchi, T. Shimizu, T. Sasagawa, H. Sekine, K. Sakaguchi, T. Kikuchi, W. Sekine, S. Sekiya, M. Yamato, M. Umezu and T. Okano, Nat. Protoc., 2012, 7, 850-858. 